\title{
"Mine is an Atypical Case": An Analysis of Life Stories about the Experience of Higher Education Drop-Out
}

\author{
Andrés Santos Sharpe ${ }^{1}$ \\ ${ }^{1}$ Instituto de Investigaciones Gino Germani, Universidad de Buenos Aires / CONICET \\ Correspondence: Andrés Santos Sharpe, Instituto de Investigaciones Gino Germani, Universidad de Buenos Aires / \\ CONICET. E-mail: andres_iss@yahoo.com.ar
}

Received: September 24, 2019

Accepted: October 11, 2019

Online Published: October 14, 2019

doi:10.5430/ijhe.v8n6p144

URL: https://doi.org/10.5430/ijhe.v8n6p144

\begin{abstract}
This paper is derived from a field study in the framework of my doctoral dissertation, in which we analyze life stories (Bertaux, 2005) of young people who have discontinued their studies at the University of Buenos Aires (UBA) in four courses with a high rate of dropout between the years 2005-2015: Computer Engineering, Anthropological Sciences, Chemical Sciences and Communication Sciences. With that goal in mind, seventy-five interviews were conducted with fifty-nine people: sixteen key informants and forty-three young people who discontinued their university studies between 2005 and 2015.

In this paper we present one aspect of the analysis: the reconstruction of the symbolic framework of the discontinuation experience from the perspective of its protagonist, and how this outlines specific types of discontinuation.
\end{abstract}

Keywords: higher education, dropout, Argentina, students experience, life stories

\section{Introduction}

This paper is derived from a field study in the framework of my doctoral dissertation (Note 1, 2), in which we analyze life stories (Bertaux, 2005) of young people who have discontinued their studies at the University of Buenos Aires (UBA) in four programs with a high rate of discontinuation between the years 2005-2015: Computer Engineering, Anthropological Sciences, Chemical Sciences and Communication Sciences. With that goal in mind, seventy-five interviews were conducted with fifty-nine people: sixteen key informants and forty-three young people who discontinued their university studies between 2005 and 2015.

In this paper I present one aspect of the analysis: the reconstruction of the symbolic framework of the discontinuation experience from the perspective of its protagonist, and how this outlines specific types of discontinuation.

The chosen decade reflects a relatively stable period in UBA regarding enrollment, abandonment, and investment rates, according to information provided by the Secretariat of University Policies.

The use of the concept of discontinuation over others (such as abandonment or desertion) favors a perspective that focuses the responsibility of the phenomenon on the student. In addition, this concept contrasts with the label that associates graduation with success and abandonment with failure.

This thesis questioned what aspects guided the decision process - conscious or not - that led to the discontinuity of university studies, which allowed us to differentiate our proposal from those that analyze the phenomenon around a central organizing idea (Dubet \& Martuccelli, 1998:87).

Considering what has been said, the research question is: what reflexivity do the subjects who discontinued their studies have on their university experience? In other words, we seek to analyze the symbolic dimensions of the discontinuation process that shape particular aspects of student experience and, in order to do that, we organized them in a typology.

For this purpose, the paper is organized as follows: first, we introduce the questions that guided this research and explain why the reconstruction of the symbolic aspects of students' discontinuation is a key factor to better understand the phenomenon. Then, we describe some central concepts for this research, such as discontinuation, choice and students' experiences. After that, we present the data collected and the methodological decisions. In this section we also characterize the period of analysis and how that is connected with the historical debate. 
In the final section, we present the results of the analysis divided into five different types based on how the interviewed people explained their discontinuation according to their student's experiences. In the conclusion, we show the scope and limits of this research.

\section{Context and Methodological Discussion}

In Argentina, university discontinuation is a phenomenon that has been increasingly present in the public agenda (Santos Sharpe, 2018). Different reports or pieces of research (Camilloni, 2000; Panaia, 2015; Guadagni, 2016) have estimated an approximate discontinuity rate greater than $70 \%$, although there are some differences in the numbers, especially because of the difficulties of accessing reliable statistical data. Panaia (2015) points out "the lack of general data of the entire system and long-term longitudinal statistical sequences." However, in the case of engineering study programs, discontinuity rates exceed approximately 50\% (Panaia, 2015:221).

Taking OECD's equation for discontinuity rates - specified in the methodological section in Annex 3 of the OECD report - Education at glance $(\mathrm{OECD}, 2016)$ - as a model, we estimated the dropout rates in different study programs of the University of Buenos Aires (UBA), in order to present some macro information on the phenomenon.

The calculation was made on 30 study programs of UBA (out of a total of 88) taking into consideration the amount of data available. At the same time, we considered study programs that had not substantially changed their study plans over the last decade (for example, in some cases there were programs in which the duration had changed from being three to five years in the study plan). Tertiary degrees, intermediate degrees and some study programs with a low number of enrollees, which in general terms have a higher percentage of graduation, were not considered. If we consider the total of UBA students, the estimated rate of discontinuity following the calculation of the OECD would be $71.75 \%$ :

Table 1 . Estimated discontinuity rates per study program at the UBA

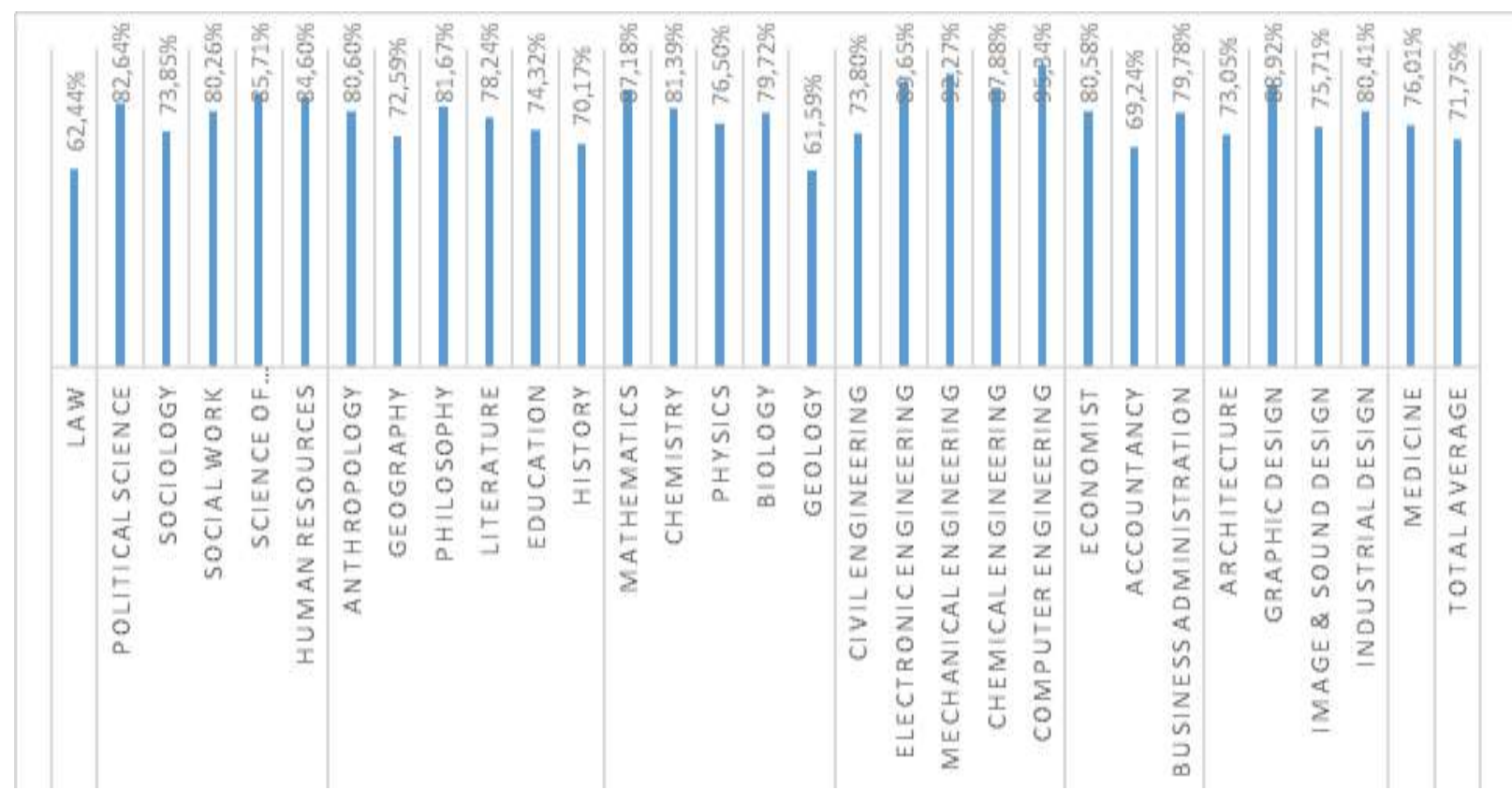

As shown in Santos Sharpe \& Carli (2016), there is little consensus in Argentina regarding how to quantify discontinuity due to the aforementioned and others difficulties, like the existence of $6.26 \%$ of students who begin two or more programs simultaneously in UBA (a high percentage when compared to other countries) and that choose afterwards which one to follow (which can inflate dropout rates). Moreover, we must acknowledge the difficulties of statistical information in Argentina, the high rate of students working while studying, and a comparatively high rate of people who enroll in one study program but never attend to it, among other issues that hinder a more precise calculation.

The construction of data on discontinuity comprises a series of assumptions and material conditions that in UBA do not appear. First, we can mention the number of students who study and work full-time, which, according to the UBA Census of 2011, is $62.7 \%$. 
Another aspect to highlight refers to the so-called "unrestricted access to university" policy. In most of the higher education systems in the world there are different modalities of selection of access, such as admission exams or quotas per study program. We consider that these selection modalities prior to admission generate invisible forms of discontinuity of studies. That is, we find people who have the genuine desire and intention of entering in a university, but who don't pass the admission exam (or who pass the exam but don't get grades high enough to enter in the pre-established quota to a specific study program); the problem is, they are not considered university students. Administratively, they are not considered students, and therefore do not appear in statistics upon which discontinuity is calculated. In UBA, on the other hand, there is no previous "filter": anyone can join any study program (Note 3).

In this research, we defined discontinuing students as those people who registered and began a university program, stopped attending it and explicitly stated that they were not going to finish it or finish another study program at the UBA.

As most studies on university discontinuity do, this research constructs the subject who discontinues their studies considering those people who enrolled in UBA and studied in its classrooms. But, unlike studies like those of the OECD, the selection of this sample is not given in terms of the theoretical duration of the degree or the average rate of graduation, but when the interviewee expresses that they do not intend to continue their higher education at UBA.

Therefore, in this paper we constructed the sample based on the subjective perception of the interviewed people about whether they intended to continue their studies or not, which differentiates them from those studies that make the cut between those who left and those who did not based on administrative data (as the theoretical duration of the study program).

Taking this into consideration, the paper discusses previous and prevalent approaches on abandonment, which, in Argentina, followed two main trends (Santos Sharpe \& Carli, 2016). These studies have in common a more systemic or structural view on the phenomenon of university discontinuation; that is, they analyze the phenomenon around a central concept. Faced with these proposals, this research performs a microsociological approach that investigates the causes of abandonment based on the analysis of the university experience, the link with the disciplinary knowledge, and the institutional culture of UBA. In other words, we seek to analyze the symbolic dimensions of the discontinuation process that shape particular aspects of the student experience.

\section{Conceptual Background}

This research aims to study the discontinuity process of university students not only from the structural causes that motivate it, (that exist and are central - for example the school of origin, the family socio-economic level, among others), but also to understand how students made that decision, which explanations they gave about it and why they constructed new life projects.

The research question sought to collect from their life stories (Bertaux, 2005) the attributed meanings that the group of students gave to the "discontinuity experience" of their studies, to their transit through the university and to the later trajectories, revealing repertoires of motifs that form decisional logics. For this purpose, we used certain conceptual categories that served to characterize aspects of the social phenomenon that was researched, specifically the concepts of "discontinuity" and "decision".

First, we will explain the election of the concept "discontinuity of studies" in order to name the phenomenon. Previous studies have used terms like "abandonment", "desertion", "drop-out", "withdrawal", "expulsion", "failure", "disengagement", and others. All these options were used in different pieces of research to describe the phenomenon and account for the different issues where the magnifying glass is focused on.

The use of the concept of discontinuity over others (like abandonment or desertion) is part of a broader discussion. We are interested in stating that the discontinuity of university studies is not an anomaly (more linked to concepts like failure), but a phenomenon that allows to explain a cluster of social relationships that go beyond the decision, traditionally considered as individual, to drop university studies.

Naming the phenomenon analyzed as "discontinuity" implies, at least, two important issues to be highlighted: first, a way of analyzing the subjects not as individuals who make autonomous decisions beyond context, but as actors who participate in a social scenario that are not necessarily guided by what is socially expected of them. This is related to the definition we give of the concept of decision. Secondly, analyzing the phenomenon as "discontinuation" allowed us to observe the ways in which subjects constructed other forms of "continuity" of their trajectories, not allowing the researcher to define those forms of continuity, a priori, in terms of success or failure. 
Regarding the concept of decision, we find that it is linked to the methodological choice of building the sample considering those who have stated having discontinued university studies and not intending to return, which differs from a more administrative or institutionalist criteria.

As mentioned at the beginning, the main focus of this research is to account for the meanings attributed to the discontinuity experience of studies. Considering this, it was crucial for the research that the people interviewed think of themselves as someone who discontinued a university program. In other words, they have made that decision.

The subjects we finally chose to interview enunciated the discontinuity as a decision that they took (imposed or self-adjudicated). This invites us to reflect on the concept of decision, which is a classic issue in the fields of action theory and political theory. In this respect, authors like Ernesto Laclau (2000:47) incorporated the concept of decision to address the constitutive aspects of the political. According to the author, a decision is not a rational choice that a person takes individually beyond all social conditioning. However, we do not suppose that the social structure defines the decisions of the subjects without any type of mediation. We recover the category of decision to address the key moment of the production of the order and the aspects related to the problem of the subject (inscribed outside any transcendentality).

\section{Study Methods}

\subsection{Introduction}

Considering all the conceptual definitions we have previously explained, we knew that the access to these experiences was going to be achieved through the stories of young people who made their decision to discontinue their university studies explicitly. The work on life stories becomes central in the investigation, as it is a window of observation of the university subjectivities; a privileged window to observe the discontinuity.

Analyzing the experiences of discontinuity from their life stories involves considering in the analysis the ways in which the subjects signify what happens to them in the world, starting from the idea that "in each narrative exists a form of social knowledge without which no apprehension of the world is possible" (Meccia, 2016:45). On the other hand, the reconstruction of the stories and the sense that the subjects grant to them implies in turn to account for "the biographical situations of the people in their relationship with the groups of belonging and reference and with the social aspect as a whole" (Meccia, 2016:42).

If life stories focus on the way subjects signify the world, we can consider them as constructions, versions of a story that the interviewee expresses to the researcher through, in this case, the interview. In other words, the subjects produce a story about what they seek to show of themselves (consciously or unconsciously); and whoever investigates, from this perspective, analyzes the form of that story.

\subsection{Life Stories on Discontinuity}

Considering this type of biographical approach, what can life stories tell us about the discontinuity of university studies? We understand that the thematic analysis of the collected stories can give us hints of the biographical crossing of the subjects by understanding the experience "as a combination of logic of action that links the actor with each of the dimensions of a system" (Dubet, 2010:96) from which they build their subjectivity and reflexivity, based on their inscription in institutional, cultural and integrative logics (Dubet, 2010).

Access to stories of young people who discontinued their studies in four selected study programs was carried out in in-depth interviews, our main objective being that the categories were provided by the stories and not defined a priori by the researcher.

In the biographical itineraries obtained from the interviews, the subjects typify their student experiences, which tell us about the inscription of their experiences within the framework of social situations. In this way, it is estimated that the experience of the subjects who discontinue their studies allows to reconstruct the heterogeneity of the individual and collective cultural practices that organize the experiences in increasingly diverse frameworks. This implies to consider that higher education today is not necessarily perceived as the end point of a predefined path, but that there are numerous possible paths that are in dispute in the decisions they make.

\subsection{Sample Construction}

Our sample was comprised of young people who have discontinued their higher education studies at the University of Buenos Aires in four study programs in four different schools with high dropout rates between the years 2005 and 2015: Anthropological Sciences, Computer Engineering, Chemical Sciences and Communication Sciences. 
The construction of the sample followed theoretical criteria (Flick, 2007:78) which included the choice of study programs and schools in which the research was conducted, the choice of young students (and discarding "older" students), and the choice of the decade in which the research was conducted (2005-2015). These were methodological choices that delimited the empirical cut of the research.

Regarding the study programs selected for the study, we considered previous studies on "student experience" at the University of Buenos Aires. Sandra Carli (2012) and Rafael Blanco (2014) showed the differences on the student experience at UBA according to the school and study program in which they were. The ways of interaction among students, the type of people who enroll in one or another study program, the profile of professors, the resources of the institutions and their ways of organization, are all very different. We suspected, as a hypothesis, that the students' experiences -and, therefore, their experience on discontinuity- were also going to be different.

In order to categorize that diversity, we considered not only the differences between scientific and humanistic disciplines, but also disciplines with a more "professional" profile and others with an "academic" profile. These differences between types of disciplines have a relative consensus among higher education studies from the work of Tony Becher "Tribes and academic territories" (2001). In his book, Becher gave an account of the cognitive dimension of the disciplines to refer to the "hard" or "soft" dimension (what we exemplify with "science" or "humanities" cases) and pure-applied ones ("professionals" or "academic").

The selection of study programs followed this chart:

Table 2. Taxonomy of Disciplinary Cultures

\begin{tabular}{ccc}
\hline Cognitive dimension & Pure (or academic) & Applied (or professional) \\
\hline Soft (or humanistic) & Anthropological Sciences & Science of Communication \\
Hard (or scientific) & Chemistry & Computer engineering
\end{tabular}

In this way we can explain the choice of the aforementioned programs with the goal of covering a wide diversity of possible experiences of disciplines. We could say that Chemistry Science is a hard and pure discipline according to Becher's criteria; while Communication Science is soft and applied. In parallel, Computer Engineering is a hard and applied discipline; while Anthropological Science is soft and pure.

This does not imply that there are not those, for example, who sign up for a study program in Communication with the idea of dedicating themselves to the academy, or chemists oriented to work in the industry. However, these are the dominant profiles in each study program which intervene in a series of dimensions such as the forms of sociability or future projections that students build in relation to their studies.

In short, we wanted to account for all those differences in the ways of studying the university, and we could only do so if we deliberately chose study programs that would account for those differences.

Parallel to these disciplinary differences, we were also interested in accounting for different institutional cultures (Remedi, 2004). By institutional cultures we understand the ways of articulation between an institutional history, the institutional practices that express (in a particular space) the history of the subjects, their daily tasks that make it possible for us to study them as unstable places of identification (2004:26-27) and trajectories, the actions and interactions of the institutional subjects.

This explains the selection of four study programs in four different schools:

1. Anthropological Science belongs to the School of Philosophy and Literature.

2. Science of Communication to the School of Social Sciences.

3. Computer Engineering to the School of Engineering.

4. Chemistry to the School of Exact and Natural Sciences.

This decision was deliberately made with the assumption that it is not the same to study in a school with a departmental organization as in the School of Exact and Natural Sciences, where most of the courses are shared with students of other study programs, that the experience in the School of Social Sciences, where the organization is more segmented by study program. The institutional culture also differs between schools in terms of material conditions (for example, the number of students per professor differs in each case, or the use of common spaces such as the library), the amount of time each type of student spends in the university building, and even the history of each study program. Additionally, to the differences in the institutional culture and in the disciplinary culture, we selected four study programs with high discontinuity rates. 
In other words, the study programs selected were not random. Moreover, the choice was not reduced only to those programs with lower graduation rates; we were interested in comparing disciplinary cultures (Becher, 2001) and institutional cultures (Remedi, 2004) to see if specific aspects of discontinuity of studies were expressed in these aspects.

The other criteria that we used to define who we contacted to interview in addition to those related to the chosen disciplines and institutions were:

1. To select subjects that have discontinued their studies between 2005 and 2015,

2. To select young people,

3. To have a balanced number of people according to gender and,

4. To consider the different moments of the study program in which they discontinued their studies (that is to say, people who had left at the beginning, in the middle and at the end of the study program).

In the first place, the chosen decade responds to a relatively stable period in the UBA regarding enrollment, discontinuity and investment levels according to information provided by the Secretariat of University Policies. If we had taken, for example, cases between the years 2000 and 2010, we should have considered the variable of the 2001/2002 economic crisis in the analysis. As it is not part of the objectives of this research to explain the discontinuity of the studies in times of economic crisis, we chose to take a period of time with no abrupt changes in economic matter.

In the second place, we sought to select young people who have discontinued their university studies, considering the category of "young" not by nature or essence (ie, not defined by a calendar age criterion), but by the study of social and cultural contexts in which the youth experience unfolds (Barobia \& Cháves, 2009).

There are two reasons why we were interested in interviewing young people - and therefore, not considering older adults in the study: first, because it is the vast majority of the university student body in the UBA. Second, because young students, as social actors, build another type of relationship with the university and with the professional expectations linked to certain life projects.

Finally, we were interested for the people interviewed to give an account of the diversity of experiences related to different stages of the program in which the discontinuity of the studies is defined; and it was interesting to consider the gender dimension in order to enter into the ways of identity construction and its performative effects on the experiences of the subjects.

In conceptual terms, it is a sample formed by theoretical criteria, that is to say: we deliberately choose how we build the sample with the objective that it be as diverse as possible in terms of the experiences of the students.

With that objective, we seek for our sample to be balanced through different qualitative criteria: types of study program, institution of belonging, gender, youth status, number of years elapsed since the decision to discontinue the program and historical moment in which they left the studies (decade 2005-2015), in programs with high rates of abandonment.

The construction of the sample involved prior research, both at a historical level on each study program and school, as well as university statistics that were analyzed in order to consider the most macro information to delimit the empirical reference of inquiry (study programs with high abandonment rates).

\section{Results}

At the beginning of the research we considered the institutional culture, the disciplinal culture and previous representations in relation to the disciplines as those central elements that the subjects recovered to build their life stories.

Understanding the different ways in which subjects make intelligible, in this case, the decision of the discontinuity of university studies, allows us to better understand the process that results in this decision. However, we know that not all the explanatory accounts are of the same type: there are different ways in which the subjects reflect on their own transit through university and different meanings attributed to the experience of discontinuity.

As the analysis of discontinuity stories progressed, we identified at least five different types of stories based on the interviews conducted. Five self-explanatory modes of the different student experiences; that is, each person interviewed developed an explanatory theory about their own experience of discontinuity in the form of thematically-modalized accounts. 
We will briefly present each of these self-explanatory theories regarding the decision to discontinue higher education and what each of them imply. It should be noted that among all the people interviewed we can recognize elements of two or more of these "types" of stories, but one of them usually predominates, from which they construct and signify their individual identities as former students of a university program.

These self-explanatory theories collaborate in making intelligible the decision to discontinue the study program as a personal decision but, at the same time, the stories are not permanent in time: the interview is the moment of elaboration of a theory about the story that they tell to themselves in the process of discontinuity. The narrative of the interview crystallizes that moment and defines, at least provisionally, the possible causes of the decision to discontinue from a retrospective glance. In other words, without a story about the key moment in which the arrangement of meaning is produced, there is no crystallization of the decision to discontinue.

\subsection{The Story of the Stranger}

In this type of story, we focus on the figure of the stranger, recovered from the work of Alfred Schütz, who defines it as an "adult individual of our times and civilization who tries to be permanently accepted or at least tolerated by the group which [s] he approaches" (2003:95).

In the interview scheme, we were interested in knowing the process of transit from the secondary school to the "Common Basic Cycle" (CBC) and, from there, to the undergraduate program: what differences they found (if any), in which aspects they had greater difficulties or accessibilities and how they considered themselves in relation to others. Among the interviewed people are those who allude to the figure of the stranger to metaphorize an alien student experience from that space but, at the same time, they notice that there are those who manage the cultural patterns of the place.

This sense of otherness in relation to the university environment appears in most of the interviews conducted, but they are expressed in different dimensions:

1) Those who feel strangers to the institutional logic of the UBA

2) Those who understand that their previous training (their previous knowledge experience) places them in a disadvantageous situation compared to their peers, understanding this dimension not only as school education, but as what could be assumed in the form of incorporated cultural capital (Bourdieu, 1987).

These dimensions are not exclusive: there are subjects who describe their student experience as "outsiders" in both dimensions and others in only one. Also, there are those who were not perceived as outsiders at any time: they are "the locals".

Just to name an example of the first kind of stranger, a Communication student mentions:

(...) [I experienced the $\mathrm{CBC}$ as a] transition between high school, where we were all happy, and the heavy work that was coming after that.

How was the admission to the School of Social Science? How did you experience it?

At that moment I began to realize a lot of things: "well, you're alone with your notebook, your pen, and make it to university early enough to get the photocopies you need because, if not, you are out", I think it was like a set of things [that collaborated to the decision of dropping out]: the feeling that you are alone with your life, I also guess that I was totally uninformed: the first day they gave me the piece of paper where you have all the subjects of the study program with the arrows which illustrate which were correlatives and which were not, I said to myself "ah, ok". I never familiarized myself with the study program, I never asked myself "well, let's see what subjects I have" (...) (Florencia, 26 years, Communication).

Here the interviewee highlights a lack of knowledge about how to get along in the UBA, comparatively with her previous school experience in a private catholic school in which, just to mention an example, the subjects were given to her by default, she couldn't choose them. Faced with this new scenario, she asked herself: What would be the criteria I should apply in order to choose the subjects I am going to study? What is a correlative? What would be the best course of study? Which teacher should I choose in each subject? Why? Where do I get that information from? These and more questions emerge as one of the new elements that the students face, and it becomes a central determinant.

Regarding self-description as a stranger in relation to previous academic knowledge, a repeated case appears in the study programs of Chemistry and Computer Engineering when dealing with mathematics: 
The problem I had with the CBC is that my high school didn't have the same level as the schools of the students that were sitting next to me at university. Those students already knew derivatives, integrals, they knew it all that and I had no idea about anything. I mean, I was far from the level of the rest of the guys who were next to me (...) (José, 33 years old, Computer Engineering).

Again, we can observe how the interviewee highlights in his student experience the sense of strangeness with respect to a specific knowledge. A crucial element that appears in all the stories of the stranger is the construction of another figure, an antagonist, which we previously defined as the "local". If the stranger stands out due to the lack of knowledge derived from his situation as a newcomer who has not managed to capture the cultural pattern of the new environment, "the local" is the mirror where the stranger looks to identify that lack of knowledge.

It should be noted that, on the one hand, not only those who have had a transition to the university in which they felt as strangers to the academic world necessarily discontinue their studies. On the other hand, not all those who described the university as a space that was strange to them at the beginning find there a reason to leave school: there are stories that mention a certain initial alienation that was later overcome.

The interviews retrieved in this first type of story refer to those subjects who indicated that the strangeness regarding the institution and/or academic knowledge and the distance with the other "locals" made the passage through university difficult for them, and, in some cases, intolerable.

These stories are more recurrent among those who discontinued their studies during the first stage of the study program, and their decision to leave the university must be related to a set of assumptions of probability or improbability -the "this is not for me" of Bourdieu (1998) as interiorization of inferiority and incapacity- that the university students bring naturalized of their previous trajectory.

\subsection{The Story of "the University is the Street"}

"The university is the street" refers to a discourse that is based on the idea that what is taught at university is anachronistic and decontextualized, and therefore what people learn at university is supposedly disconnected from what they call "the real world".

It is not the intention here to reconstruct how this discourse arises or what its ideological substratum is; but we would mainly like to emphasize that this discourse exists and circulates in different spheres. What is of interest for us is that this discourse is present and has a certain degree of appeal in certain university students who, in turn, build a story in which they explain their decisions on dropping out around the dichotomy of academia vs. real world, understanding by "real world" the professional practice.

In which type of students do we observe the greatest recurrence of this story? If "the story of the stranger" was more prevalent among those who discontinued their studies at the beginning of the study program, we observed that "the university is the street" is more disciplinarily segmented: it is people interviewed from professional careers who wield it most frequently.

Taking as an example the case of an interviewee who discontinued the study program on Computer Engineering:

(...) the other specific issue of this study program that I see as a common factor with many people I spoke with is the distance between what you see at university and how you can apply it in your daily work. That is, Computer Engineering is... everyone says it is a discipline that advances very rapidly, and I understand that universities are not able to go hand in hand with that, but they should try. At least what I have noticed in my experience is that you go to university and you say "they are teaching me how to make a black and white television and we are actually using a Smart TV". And after that, you start to demoralize (Christian, 32 years old, Computer Engineering).

Those discourses expressed in terms of "what is taught in the university" as opposed to "what happens in business life" among those who discontinued the study program in Computer Engineering, are expressed as the dichotomy of theory / practice in Science of Communication:

(...) I was bored all the time and I guess it was also because [the study program] was theoretically dense. I didn't feel it was difficult, because it didn't demand too much effort. I understood everything and I did well, but everything was like very repetitive and it never reached something concrete ... it made me remember when they teach you in high school, I don't know, derivatives in mathematics and you say "Where will I use this?" I felt that. But the problem was that I had chosen this profession to work my entire life. So I asked to myself, what am I going to use it for? 
I have chosen this and I don't know what I'm going to use it for! (Camila_1, 26 years, Sciences of Communication).

Enunciated in different ways, we observed in the professional disciplines (mainly in Computer Science, and to a lesser extent in Communication) a greater weight of the story of "the university is the street", which is highlighted by the enunciation of a search of a professional or practical utility of the knowledge, and by the statement in which that practical knowledge is apprehended, in fact, outside the university.

\subsection{The Story of the Rejection to the University}

The rejection story maintains certain similarities with the previous case. It is used by those who argue that they have discontinued their studies because the university or the chosen study program has certain characteristics that seem anachronistic to them or that are not formative for the chosen profession.

But, unlike "the university is the street", the criticism to the university is not geared towards what kind of knowledge a study program should teach that might be considered valid or useful. It mainly concentrates its criticism towards university in both its organization, in the ways of teaching and evaluating of their teachers, and in the disciplinary traditions of teaching.

A student of Chemistry explained the differences between the content and the ways of evaluation in her student experience. This contrast was a constant throughout the study program, and she gave an example with one subject:

Analytical Chemistry is a subject that I loved, I enjoyed it, it is beautiful, you learn a lot but the way they evaluate you is shit.

Why?

Because... according to them if I teach you "A", in the evaluation I have to test "A" plus "B". Because if you understood "A" by yourself, you have to be able to do a little bit more. That time, I did all the guides, I did perfect, but in the exam there was always something else, and that "something" you have to do it by yourself. And for them that's fine. A professor in didactics told me that if I teach you "A" and I ask for "B" in the exam I'm being dishonest, and I agree with him, but professors in Chemistry don't seem to agree. They understand that that's part of being a scientist: if I ask you in the exam for the same thing that I taught you, you will not learn anything according to them. But, tell me: have you ever seen a scientist who works completely alone? (Paula, 26 years old, Chemistry).

This reasoning is observed in different stories of the same study program: there was a specific way of evaluating, that was predominant in that discipline that, according to the interviewed people, ends up damaging those who "have more difficulties" and makes the student experience an unpleasant one, even in a subject whose contents you may like.

The causes for experiencing rejection towards the university or the discipline are, however, diverse. For example, two female students in Computer Engineering explain that the study program is eminently masculinized and how that makes it difficult for women to remain here. Just to mention one example:

If you don't have a previous study group, in my opinion it's impossible for a girl to get into a good group (...) you have to "earn your place". So, that is what I saw as a differential obstacle between men and women (Carolina, 32 years old, Computer Engineering).

The Rejection Story has as characteristic the heterogeneity of disciplines in which it takes place. Its manifestation is not circumscribed eminently to one study program or another, nor to a type of knowledge, but to how certain traditions, styles or characteristics of the study program intervene negatively in the student experience. As an example, we can notice this type of story in Sciences of Communication:

I was close to the university building. It's not that I could use that I was far from it as an excuse. I worked, I have always worked since I was 15 , but I had time enough to study without any problems. My other activities didn't interfere with my studies. In other words, it happened [meaning, the dropout] simply because I didn't like... the structure (Camila_2, 27 years old, Sciences of Communication).

As can be seen, the interviewee constructs a story of discontinuity that doesn't have as a main argument the fact that she has failed one or several exams; she focuses on the ways of evaluating. Unlike the story of "the university is the street", which was more present in the professional types of study programs (and particularly in Computer 
Engineering, because of the good job opportunities it provides), the "story of rejection to the university" is more transversal to the four study programs analyzed. There is a greater primacy of the rejection story among those who discontinued their studies in the first stages of their studies, but there are also those who discontinued in the middle of their studies or towards the end (who mention that they "persisted" in their studies because of shame, pride, or prestige associated with the certificate, and that they consider that they should have discontinued before).

The rejection story is opposed to the idea of failure: the subject does not feel it fails, it is the institution (the university or study program in particular) or "the education system" the one that fails. The interviewed people who identify themselves into this story state that they didn't do poorly or that studying wasn't difficult for them (generally, they showed as examples the grades that they had in different subjects), but the problem for them was the institutional culture of the university and the study program (and their respective ways of teaching, evaluating and socializing within each space) which generated a rejection that sooner or later crystallized in the discontinuity of their higher education studies.

\subsection{The Vocational Story}

The "vocational story" refers to those stories that explain the discontinuity of a study program because the interviewed person discovered their "true vocation", which, for them, was previously "hidden". A vocation is commonly understood as something that is born from within, an innate predisposition that "is discovered". However, not all professions build a strong "vocational identity". We can recognize in the public discourse the idea of vocation as "artistic vocation", "medical vocation" or "teaching vocation", but perhaps we have never heard the term vocation associated with the job of a secretary, operator in a factory or business administration.

In this way, we would like to highlight two aspects: first, that there are stories constructed based on the belief that there are vocations or innate gifts to the subject which are revealed in a moment in life. Often, those are associated with professions that involve a service to the community and that are carried out with a certain degree of disinterest and passion.

The second aspect is intimately linked with the idea that there is an essence in the professional or academic identity construction. This idea is related to this attributed sense that the vocation arises "from the inside" of the person. In other words, the story essentializes explanations about discontinuity. For example, one interviewee who discontinued Sciences of Communication said:

(...) particularly what drove me to change was the fact that my true vocation was really oriented towards dancing. Now I am a dance teacher, and for the three years I was at university I dropped dancing. I supplanted it for another thing: studying, and after being at university, with all that that implied, I realized that it was not for me (...) (Florencia, 26 years, Sciences of Communication).

In this case, the interviewee explicitly mentions in this extract and in others that she discontinued her university studies because it took her a long time to "realize what my true vocation was". Other interviewed people, similarly, built a story of self-discovery in which they narrate that in college they had a bad time and after a while they rediscovered their passion, as observed in this interview of someone who discontinued Anthropology:

(...) I was there, reading some shitty photocopies. It was fucking boring. They talked to me about fabulous things but there was "something" missing in me. And I felt anguish on that aspect, and while doing that I started again with photography and documentary. And I began to make photography and documentary workshops, in parallel to Anthropology. And in that moment, I started to find something that I liked more (Juan, 29 years old, Anthropology).

In this type of story, the interviewees developed subjective theories in which, in their argumentative structure, they compare the reluctance that the university study program produced to them with the passion that generated their new path followed in their post-university trajectories. Also, all the stories of vocation (or self-discovery) narrate that there was already a prior interest in that vocation, and they determine a key moment (a turning point) of their biographical experience as an event that awakened their vocation.

Contrary to what was expected at the beginning of the analysis, this type of story was more frequent in humanistic disciplines (in this study: Communication and Anthropology). The analyzed Science study programs hold a greater passion share in the stories in relation to the chosen discipline in spite of having discontinued the studies.

\subsection{The Story of the Crossroads}

The last type of story integrates those interviews that describe their university experience as pleasurable and the discontinuation of studies propelled by "external reasons". Briefly, they explain the reasons for the discontinuity of 
the study program as reasons that were imposed on them; they express that they would have liked to finish their studies but found themselves in a situation in which they had to make a decision between two opposing options.

For the story of the crossroads we recover the expression of turning point by Daniel Bertaux (1981), also known as "hinge moment", "carrefour" or "inflection point" (Kornblit, 2007:22-23), understood as episodes in the life of the subjects when they experience a change where they have to make a decision between two possible trajectories. In the case of the interviews conducted, the crossroads are defined by whether continuing studying at university or following another course of action presented to them, which differs in each case.

Unlike the previous cases, in the story of the crossroads the interviewed people maintain their desire to finish higher education studies. If it were not like that, there would be no conflict: they would decide on the second option of the crossroad. However, the particular feature of this story is that they are presented with two possible but incompatible life paths: they have to make a decision. For example, one subject who discontinued Chemistry said:

No, in my case, last year, the last semester I didn't sign up for any subject of the study program... that was like the turning point when I said "no, I have to slow down, I need another lifestyle" because I got a nervous breakdown... well I had to get hospitalized because half of my body was paralyzed because of stress (...) but that was the turning point: during the first quarter of 2011, and I said "no, I'll look for something else to study because although I love Chemistry, I don't want to put my life at risk or decide between life or study", that's why I ended up deciding to dropout (Vanina, 25 years old, Chemistry)

In this case the interviewed person identifies a specific moment as a "turning point" in which she had to decide between continuing her studies or prioritizing her health. Towards the end of her story, the interviewee mentions that she continued her studies in a technical-school, in which she's studying something related with chemistry and she assures that she always liked the discipline, but that she could not bear the stress and studying under those conditions.

Let's see the case of a Communication student, who at one point in the interview asked me how old I was then. We were the same age and he started building his argument from that bit of information: there is a time to study at university, and he understands that moment was gone for him:

I chose to continue with my job at that moment, which is something that I am already involved in and that I know a lot of companies and people connected to that job, and maybe one day I can grow within the company. I was talking about it with my girlfriend the other day, I think I'm working in order to be economically stable, and I'm not doing what I would really like to do. It's sad, but I think it's life (Nico, 28 years old, Communication).

The lack (manqué) always operates in this story and it can be seen that the stories name an "external agent" that led them to make the decision to discontinue the studies, despite the person being involved. In the case of the last interviewee, that "external agent" is what he calls "the system", that in the analysis we translated as the obligation he feels that at a certain moment in life he must be independent and eventually prepared to start a family.

This type of story, as in the case of the "rejection story", is also disciplinarily heterogeneous, although it was less frequent among Computer Engineering interviewees: even those who didn't finish their studies are able to continue the connection with the discipline without needing a diploma, given that the labor market of that field is open to incorporate people without diplomas, so there is no feeling of desolation in the stories.

The heterogeneity of this group is also observed at the moment they choose to discontinue their studies: we found people who discontinued in a balanced way in different instances of their study programs. They all have in common the emergence of an identifiable "cause" by which they had to leave the study program. A kind of "detonator", be it a serious health situation, the need to move to another city, the impossibility of sustaining themselves economically, the feeling that "I am already too old to be at university" or something else, but in the final analysis it is something clearly identifiable by the people interviewed.

In this sense, it partially resembles the "story of the stranger" insofar as the university is presented as an impossibility, but while in the first story this impossibility is given from the "inside" (the people interviewed are the ones that internalize the impossibility of finishing their studies as something related with their previous educational and cultural trajectories), in this story the impossibility is given from "the outside": there is a factor stated as external that forces them to make a painful decision (discontinuing higher education) which in other circumstances they would not have taken. 
By the end of this paper, we will sketch some closing comments recovering the conclusions derived from the five types of stories, always considering, as previously mentioned, that the present characterization of "types of stories" does not mean that each person interviewed adheres, consciously or unconsciously and without nuances, to one of the stories and excludes mediations of the rest from their student experience. However, we understand that in the explanations outlined in the interviews in relation to the decision to discontinue, a type of story predominates, from which they construct and signify their individual identities as former students of a university program.

\section{Conclusions}

Our general objective throughout the paper was to understand the attributed meanings that students give to the "experience of discontinuing their studies" on different study programs, to their transit through university, and to the subsequent trajectories, revealing repertoires of motives that form decisional logics on discontinuity.

Prior to the section of analysis, we outlined the particular methodological and theoretical path our research went through: from the approach of the problem and objectives, through the main concepts we use, we exposed the chosen biographical notion (life stories) and finally we developed the theoretical-methodological corpus that allowed us to analyze the problem.

In general terms, the "types of stories" that the interviewed people construct in order to explain the discontinuity of higher studies does not account for a story common to all; on the contrary, it can be observed that there are elements of the institutional, disciplinary and representational cultures that are shaping (increasingly) divergent stories.

The first thing that can be observed as a corollary of the research is the diversity of meanings and significance given to each attribute by each type of story. We understand that this diversity shows that the student social group can no longer be defined by its homogeneity organized from a center, nor by a rational choice, nor by a logic of reproduction of a cultural program precisely due to the heterogeneity of cultural and social principles that organize behaviors in which "individuals are driven to administer various logics of action" (Dubet, 2010:227).

These aspects are related to broader social and conjunctural transformations. We understand that the ways in which students discontinue a study program have undergone transformations since the first studies on university dropout in the 1960s (Santos Sharpe \& Carli, 2016) and that the stories of the interviewed people show that the reasons derive in specific ways of discontinuing studies are increasingly complex and heterogeneous for various reasons: transformations in work expectations, transformations in the meanings of university education, and given that there are multiple possible life trajectories and that certain social learnings that do not happen in the same way to everybody at any time. The juvenile and student condition also operates in that context.

The second contribution of the research refers to the performative effect of the student experience and the symbolic-representational dimension in the discontinuity of university studies. The life-story is nourished by the student experience and, at the same time, defines in part the times and ways of discontinuity, which can be seen in the fact that one of the attributes with the greatest significance in the types of stories was the importance attributed to the moment in which the person decided to discontinue the study program.

On the other hand, attributes historically considered as more significant in the analysis on discontinuity, such as the entity given to the grades as an explanation, were not significant at the time of making the decision to discontinue higher education in this study. That is, the people interviewed tell that they did not discontinue due to good or bad grades, that decision went through other issues.

So, if we wanted to develop institutional policies to mitigate discontinuity, how can we not consider the reasons that the subjects wield and that make the decision they made intelligible? As it was said before: without a story about the key moment of the production order there is no crystallization of the decision to discontinue.

\section{References}

Barobia, R. \& Cháves, M. (2009). Eje abordajes teórico metodológicos. In M. Cháves, Estudios sobre juventudes en Argentina I. Hacia un estado del arte 2007, 17-22. La Plata: UNLP.

Becher, T. (2001). Tribus y territorios académicos. La indagación intelectual y las culturas de las disciplinas. Barcelona: Gedisa.

Bertaux, D. (1981). Biography and Society. The Life History Approach in the Social Sciences. London: Sage.

Bertaux, D. (2005). Los relatos de vida: perspectiva etnosociológica. Barcelona: Bellaterra.

Blanco, R. (2014). Universidad íntima y sexualidades públicas. La gestión de la identidad en la experiencia estudiantil. Buenos Aires: Miño y Dávila. 
Bourdieu, P. (1987). Los tres estados del capital cultural. Sociológica, 2(5), 11-17. Retrieved from http://www.sociologicamexico.azc.uam.mx/index.php/Sociologica/article/view/1043/1015

Bourdieu, P. (1998). La distinción. Críticas y bases sociales del gusto. Madrid: Taurus.

Camilloni, A. (2000). Indicadores de rendimiento interno según facultades y carreras (1992-2000). Buenos Aires: Secretaría Académica UBA.

Carli, S. (2012). El estudiante universitario. Hacia una historia del presente de la educación pública. Buenos Aires: Siglo XXI.

Dubet, F. (2010). Crisis de la transmisión y declive de la institución. Política y Sociedad, 47(2), 15-25. Retrieved from https://revistas.ucm.es/index.php/POSO/article/view/POSO1010230015A/21582

Dubet, F. \& Martuccelli, D. (1998). En la escuela. Sociología de la experiencia escolar. Buenos Aires: Losada.

Flick, U. (2007). Introducción a la investigación cualitativa. Madrid: Morata.

Guadagni, A. (2016). Nuestra graduación universitaria es escasa. Boletín CEA №19. Buenos Aires: Universidad de Belgrano.

Kornblit, A. 1. (2007). Historias y relatos de vida: una herramienta clave en metodologías cualitativas. En A. 1. Kornblit, Metodologías cualitativas en ciencias sociales. Modelos y procedimientos de análisis, 15-34. Buenos Aires: Biblos.

Laclau, E. (2000). Nuevas reflexiones sobre la revolución de nuestro tiempo. Buenos Aires: Nueva Visión.

Meccia, E. (2016). El tiempo no para: los últimos homosexuales cuentan la historia. Santa Fe: Ediciones UNL-Eudeba.

Meccia, E. (Dir.) (2019). Biografías y sociedad. Métodos y perspectivas. Santa Fe: ediciones UNL - EUDEBA.

OECD (2016). Education at a Glance 2016: OECD Indicators. París: OECD Publishing. https://doi.org/10.1787/eag-2016-en

Panaia, M. (2015). Universidades en cambio: ¿generalistas o profesionalizantes? Buenos Aires: Miño y Dávila.

Remedi, E. (2004). La institución: un entrecruzamiento de textos. En E. Remedi Allione, Instituciones educativas. Sujetos, historia e identidades, 25-58. México: Plaza y Valdez.

Santos Sharpe, A. (2018). El discurso de la prensa gráfica sobre el abandono universitario. La educación superior como bien individual. Question, 1(59), e077. https://doi.org/10.24215/16696581e077

Santos Sharpe, A. \& Carli, S. (2016). Estudios globales y locales sobre el abandono de los estudios universitarios. Teorías, perspectivas y nuevos abordajes. Revista Argentina de Educación Superior (RAES), 8(13), 6-31. Retrieved from http://www.revistaraes.net/revistas/raes13_art1.pdf

Schültz, A. (2003). Estudios sobre teoría social. Buenos Aires: Amorrortu.

\section{Notes}

Note 1. Santos Sharpe's Doctoral dissertation. Universidad de Buenos Aires, Buenos Aires.

Note 2. A preliminary version of this paper was published in Meccia (2019).

Note 3. For a general perspective on the Argentinean HES, refer to http://dx.doi.org/10.4236/ce.2015.618200

Note 4. The CBC is a common cycle for most of the study programs at the UBA designed to ensure a standardized academic background for all students seeking undergraduate degrees. Only upon completion of this first year may the student enter the chosen school, but students at the $\mathrm{CBC}$ are considered undergraduate students of the UBA. 